\title{
Effect of UVC rays on biomass production by Nomuraea rileyi (Farlow) Samson when mixed with various adjuvants
}

\author{
S.D. PATIL* AND A.P. PADHYE
}

Agricultural Research Station, Niphad, NASIK (M.S) INDIA

\section{ARITCLE INFO}

Received : 18.08 .2015

Revised : 03.09 .2015

Accepted : 19.09 .2015

\section{KEY WORDS :}

Nomuraea rileyi, Media, Yeast extract, Ultraviolet formulations, Biomass

*Corresponding author:

Email: saurushrutu@gmail.com

\begin{abstract}
The effect of UVC rays on the viability of entomopathogenic fungus, Metarhizium anisopliae (Metschinikoff) Sorokin, in the presence of various concentrations of adjuvants comprising glycerol (1.0, 2.0, 3.0 and 5.0\%), tween-80 (0.5 and 1.0\%), boric acid (1.0, 2.0 and $3.0 \%)$, carboxymethyl cellulose $(0.5$ and $1.0 \%)$, indigo $(0.5$ and $1.0 \%)$, turmeric $(0.5$ and $1.0 \%)$, molasses $(0.5$ and $1.0 \%)$, honey $(1.0$ and $2.0 \%)$, milk (1.0 and $2.0 \%)$, sunflower oil $(0.5$ and $1.0 \%)$, groundnut oil $(0.5,1.0$ and $2.0 \%)$, mustard oil $(0.5$ and $1.0 \%)$, soybean oil $(0.5$ and $1.0 \%)$ and ghee $(0.5$ and $1.0 \%)$ and formulations without adjuvants, when exposed for 10 to 50 minutes, 2, 3 and 5 hours was studied under laboratory conditions. The UVC rays proved detrimental to the fungus and the effect increased with increase in exposure period. After 5 hours exposure to UVC rays, N.r.+SFO 1.0 per cent produced highest $(4.97 \mathrm{~g})$ biomass when it was in rest of the treatments (2.40 to $4.87 \mathrm{~g}$ ) against $1.80 \mathrm{~g}$ in control (N.r. alone). The next promising treatments were N.r.+SFO 0.5 per cent $(4.87 \mathrm{~g}), N . r .+$ GNO 1.0 per cent $(4.87 \mathrm{~g})$ and N.r.+GNO 2.0 per cent $(4.77 \mathrm{~g})$. The control N.r.alone without UVC exposure produced $7.30 \mathrm{~g}$ of fungal biomass. Among the various oils sunflower and groundnut oil, among chemical adjuvant glycerol 2.0 per cent, CMC 0.50 per cent, boric acid and among nutrient sources honey, milk act as appreciable UVC protectant.
\end{abstract}

How to view point the article : Patil, S.D. and Padhye, A.P. (2015). Effect of UVC rays on biomass production by Nomuraea rileyi (Farlow) Samson when mixed with various adjuvants. Internat. J. Plant Protec., 8(2) : 352-358. 